|| ISSN(online): 2589-8698 || ISSN(print): 2589-868X || International Journal of Medical and Biomedical Studies

Available Online at www.ijmbs.info

PubMed (National Library of Medicine ID: 101738825)

Index Copernicus Value 2018: 75.71

Prospective Study Article

Volume 3, Issue 4; April: 2019; Page No. 187-192

\title{
TO CORRELATE FOETAL OUTCOME WITH GROSS AND MICROSCOPIC PLACENTAL CHANGES.
}

\author{
Dr. Akanksha Jain ${ }^{1}$ (Demonstrator) \& Dr. Garima Dhamnani ${ }^{2}$ (Senior Resident) \\ ${ }^{1}$ Bundelkhand Medical College, Sagar \\ ${ }^{2}$ Sri Aurbindo Medical College and P.G. Institute, Indore
}

Article Info: Received 10 April 2019; Accepted 25 April. 2019

Cite this article as: Jain, Dr. A., \& Dhamnani, Dr. G. (2019). TO CORRELATE FOETAL OUTCOME WITH GROSS AND MICROSCOPIC PLACENTAL CHANGES. International Journal of Medical and Biomedical Studies, 3(4).

DOI: https://doi.org/10.32553/ijmbs.v3i4.217

Address for Correspondence: Dr. Garima Dhamnani, Sri Aurbindo Medical College and P.G. Institute, Indore Conflict of interest: No conflict of interest.

\section{Abstract}

Background: This is a prospective type of study and constitutes the clinicopathological correlation of abnormal placental findings with pregnancy related maternal morbidities and associated foetal outcome in all preterm and full term pregnancies. Placentae from 80 deliveries of preterm and fullterm gestation were collected from labour room of Bundelkhand Medical College, Sagar during the period from June 2017 to June 2018.

The gross features of placenta varies significantly with period of gestation. Parameters such as weight, size, number of cotyledons and thickness of placenta decreases in preterm labour. The microscopic lesions observed in decreasing order of frequency were perivillous fibrin deposition (62.50\%) followed by chorioamnionitis $(26.25 \%)$, infarct $(21.25 \%)$ and calcification $(17.50 \%)$. Other pathological lesions includes villous oedema (12.50\%) and retro placental hematoma (2.50\%). All the histomorphological changes were conspicuous in preterm pregnancies.

Keywords: Foetal, Gross, Microscopic \& Placental

\section{Introduction:}

The placenta is the most accurate record of infant's prenatal experiences. Generally physicians are uncomfortable with the task of examining the placenta, but according to Benirschke1 it is a task they should willingly undertake because submitting this organ to a knowledgeable look and touch can provide much insight into prenatal life. Structural and functional derangement of placenta, evoke a considerable interest, as these may be the only yardsticks to measure adequacy of the foetal environment. $^{[1]}$
The intrauterine existence of fetus is dependent on one vital organ "The Placenta". Placenta is essential for maintenance of pregnancy and for promoting normal growth and development of fetus. ${ }^{[2]}$ It is the most accurate record of the infant's prenatal experience. ${ }^{[3]}$ It forms the morphological record of anatomical condition, intrauterine events and intrapartum events of gestation. As placenta is the mirror of maternal and fetal status, it reflects the changes due to maternal hypertension.

The fetus is dependent on the placenta for maintaining and promoting normal development. In pregnancy induced hypertension, pathological changes in the 
placenta such as infarction, calcifications, diffuse placental thrombosis, inflammatory placental vasculopathy and abnormal trophoblastic proliferation occur resulting in reduced blood flow across placenta and uteroplacental insufficiency. ${ }^{[4]}$

\section{Material \& Method}

This is a prospective type of study and constitutes the clinicopathological correlation of abnormal placental findings with pregnancy related maternal morbidities and associated foetal outcome in all preterm and full term pregnancies. Placentae from 80 deliveries of preterm and full term gestation were collected from labour room of Bundelkhand Medical College, Sagar during the period from June 2017 to June 2018.

For the study the cases were selected which fulfill the inclusion criteria such as all singleton pregnancies, all twin pregnancies, cases who presented with gestation period of $<37$ weeks, all patients with haemoglobin level of $<11 \mathrm{gm} / \mathrm{dl}$; cases associated with foetal abnormalities including low birth weight, IUGR and IUD.

We have excluded all the cases who had any associated systemic disorders like diabetes mellitus, preelampsia, eclampsia, SLE, CNS disorders like epilepsy, poliomyelitis, polyneuritis and psychiatric disorders, rheumatic heart disease and pulmonary disorders like pneumonia and COPD; established cases of haemoglobinopathies and other haemoglobin disorders less anaemia and patients who were not willing to participate in study.

The cohort of patients with singleton uncomplicated term pregnancy, foetus with birth weight of $\geq 2.5 \mathrm{Kg}$, gestational period of $>37$ weeks, blood pressure $<140 / 90 \mathrm{~mm}$ of $\mathrm{Hg}$ throughout pregnancy and haemoglobin value of $\geq 11 \mathrm{~g} / \mathrm{dl}$ formed the control group.

After taking the informed consent of the selected cases, the placenta was collected after delivery or caesarean section in a wide mouthed plastic or glass container. It was preserved in $10 \%$ neutral buffered formalin and kept for overnight fixation. The relevant data of the patients for this study such as patient's name, age, period of gestation, gestational score, haemoglobin levels, relevant sonographic findings and any significant clinical history were recorded in the separate clinical proforma for each case (Annexure I). Data about foetal outcome including foetal birth weight, sex and Apgar score were recorded separately in the master chart.

All placentae were received fresh and examined for gross pathology. Features such as shape (normal placenta is discoid shaped), size (normal size 15-20 cm), thickness (normal thickness 2.5 $\mathrm{cm}$ at the centre), weight (normal weight is 500 $\mathrm{gm})$, completeness of amniotic membranes, umbilical cord, foetal surface and cotyledons, degenerative changes and presence of any separate lobe were noted. The umbilical cord was assessed for length, colour, presence or absence of true knots, number of vessels and insertion on foetal surface. The membranes were examined for completeness, insertion, oedema, extra amniotic pregnancy, retromembranous haemorrhage, meconium staining and opacity. In case of twin delivery the chorionicity was evaluated by examining the interwining of membranes. The foetal surface was examined for colour, opacity, cysts, thrombosis of vessels and chorangioma. The maternal surface was evaluated for laceration, number of cotyledons, infarction and retroplacental haemorrhage.

The following gross placental pathological lesions were recorded:

(a) Placental infarction- Which appears as thick, stiffened and pale area. Early infarcts are red but as the infarct ages its colour blanches from pale yellow to white.

(b) Chorangioma- Which appears as small haemorrhagic area or rarely as a large mass bulging on the foetal surface. The diagnosis was established on microscopic examination of the tissue.

(c) Subchorial fibrin deposition- It presents as firm, oval, tan white and slightly raised plaques 
on the foetal surface beneath the amnion and chorion.

(d) Retroplacental hematoma- Recent haematomas are soft, red and gets easily dislodged whereas older haematomas are firm, brown and adherent to placenta.

The findings were recorded in standard proforma of placental examination. After fixation, representative sections of $3-5 \mathrm{~mm}$ thickness were submitted for routine histological examination. These sections consisted of two umbilical cord sections taken from foetal point of attachment and other from placental insertion point, a membrane roll sampled from rupture site and a further random site, one full-thickness placental tissue, and section(s) from any macroscopically pathologic area.

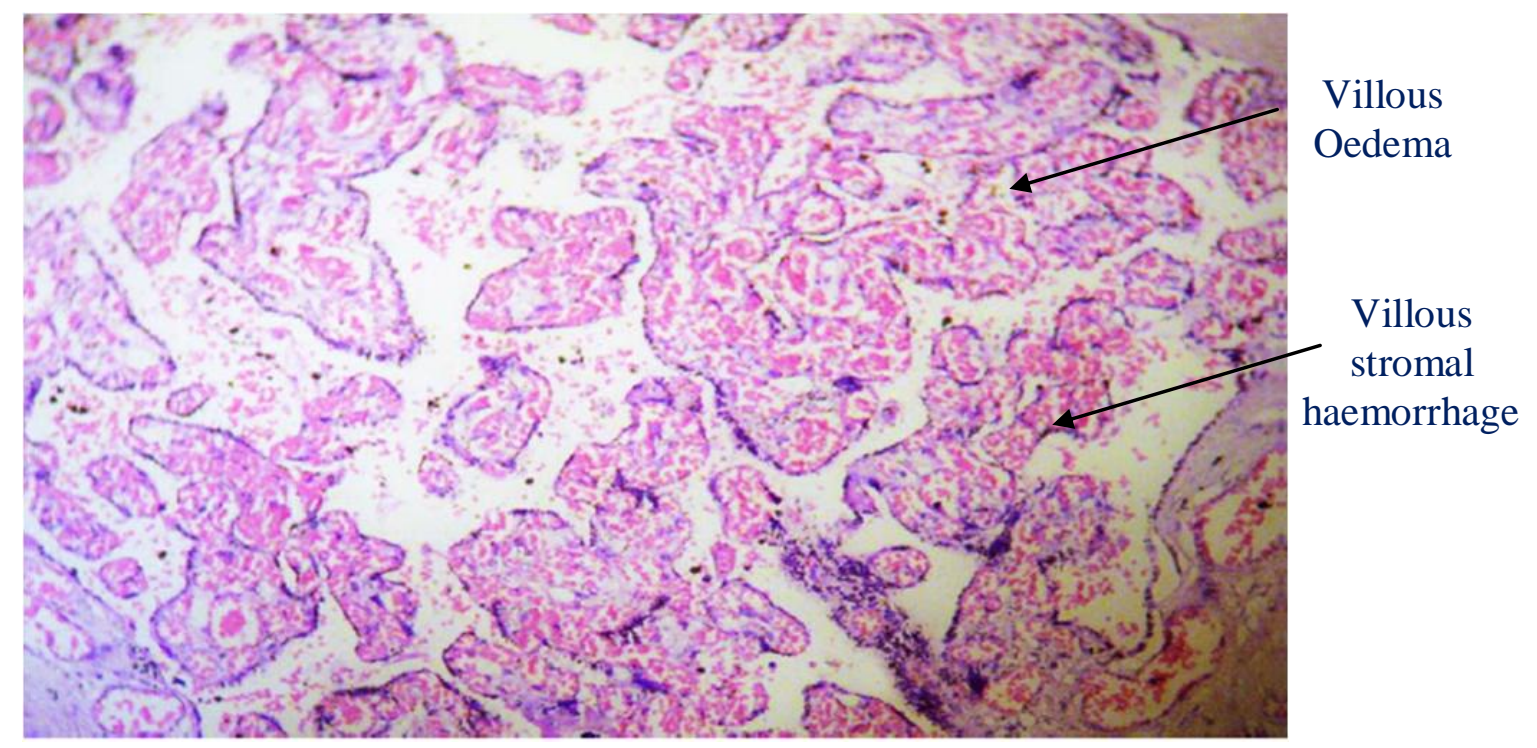

Figure 1: Photomicrograph showing oedematous villious stroma with extensive areas of intravillous haemorrhage $(100 x)$.

\section{Results}

Table 1: Gross Examination

\begin{tabular}{|l|l|l|}
\hline Gross & Pre-term & Term \\
\hline Weight (gms) & & \\
$(1)<300$ & $10 \%$ & $0.00 \%$ \\
$(2) 301-400$ & $21.2 \%$ & $27.50 \%$ \\
$(3) 401-500$ & $8.75 \%$ & $26.20 \%$ \\
$(4)>500$ & $2.5 \%$ & $3.75 \%$ \\
\hline Size & & \\
$(1) 10-12$ & $10.0 \%$ & $0.00 \%$ \\
$(2) 13-15$ & $20.0 \%$ & $26.20 \%$ \\
$(3)>15$ & $12.5 \%$ & $31.20 \%$ \\
\hline No. of Cotyledon & & \\
$(1)<10$ & $11.2 \%$ & $2.5 \%$ \\
$(2) 11-13$ & $10 \%$ & $30 \%$ \\
$(3) 14-16$ & $20 \%$ & $22.5 \%$ \\
$(4)>16$ & $1.23 \%$ & $2.5 \%$ \\
\hline Thickness(cm) & & \\
$(1)<2.74$ & $16.2 \%$ & $6.2 \%$ \\
$(2)>2.75$ & $26.2 \%$ & $51.2 \%$ \\
\hline
\end{tabular}


Dr. Akanksha Jain et al, International Journal of Medical and Biomedical Studies (IJMBS)

\begin{tabular}{|l|l|l|}
\hline Gross & Pre-term & Term \\
\hline Meconium Staining & $5 \%$ & $2.5 \%$ \\
\hline Transparency of membrane & $22.2 \%$ & $52.5 \%$ \\
\hline Length of cord & & \\
$(1)<10$ & $8.7 \%$ & $1.2 \%$ \\
$(2) 11-15$ & $3.7 \%$ & $5 \%$ \\
$(3) 15-20$ & $12.5 \%$ & $7.5 \%$ \\
(4)>20 & $17.5 \%$ & $43.7 \%$ \\
\hline Attachment of cord & & \\
(1) Eccentric & $40 \%$ & $57.5 \%$ \\
(2) Battledore & $2.5 \%$ & ----- \\
\hline
\end{tabular}

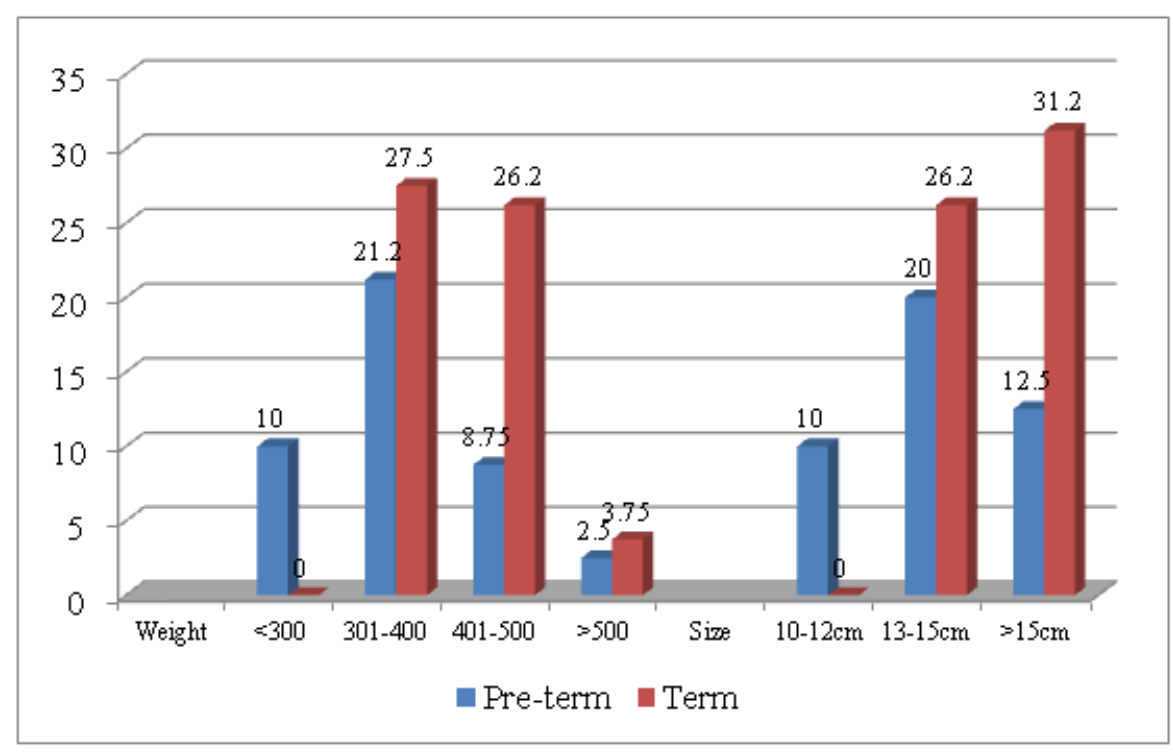

Graph 1:

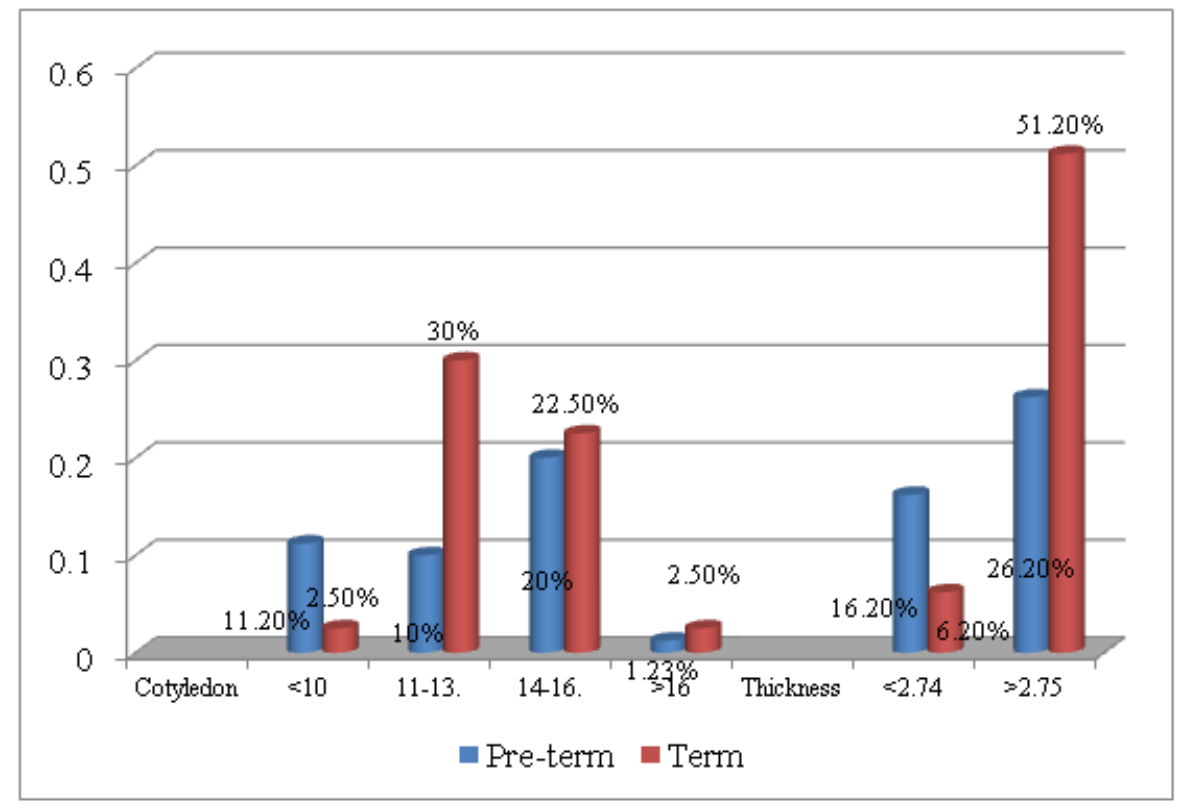

Graph 2:

The weight, size, number of cotyledons and thickness of placenta increases with period of gestation. The mean weight, size, number of cotyledons and thickness of placentae being $414.12 \mathrm{~kg}, 15.42 \mathrm{cms}, 13.2$ and $2.84 \mathrm{cms}$ respectively. 
Increased incidence of meconium staining was observed with preterm deliveries (5\%). Similarly $52.50 \%$ full term pregnancies showed transparent membranes indicating higher incidence of chorioamnionitis with preterm deliveries.

There was no significant association between length of cord and period of gestation. The majority of cases showed eccentric attachment of cord with only $2.50 \%$ of preterm cases showing battledore insertion.

\section{Discussion}

Histopathological examinations of the placenta can reveal changes which may be associated with maternal disorders and result in adverse foetal outcome. Placental studies are quantitative rather than qualitative, as some changes take place in placenta before it separates from the uterus. The changes are considered pathological when the extent of involvement is greater than normal ${ }^{[5]}$. The present study was carried out to compare various parameters of placental histopathology and their significance with foetal outcome.

CHEN KH et al reported adverse maternal and foetal outcomes associated with placental calcification. Maternal outcomes includes postpartum haemorrhage (12.1\%), placental abruption (6.8\%) and maternal transfer to the intensive care unit (6.8\%). Adverse foetal outcomes included preterm delivery (17.9\%), low birth weight (26.9\%), low Apgar score (11.1\%) and neonatal death $(5.3 \%)^{[6]}$.

Navbir $\mathrm{P}$ reported placental calcification in 73.34\% cases of various grades of hypertensive pregnancies. However, $10 \%$ of the placentae from the control group also showed calcification. Thus, placental calcification was seen more commonly in placentae from hypertensive patients. Similar findings have been reported in this regard by Fox, Shanklin and Mehrotra et al. A correlation between placental calcification and primigravidity has been noted in the study by the author. $72.73 \%$ placentae in the study group, showing calcification, were from primigravidae as compared to $33.3 \%$ from the control group ${ }^{[7]}$. This relationship between placental calcification and primigravidity has also been reported by Fox and Wentworth ${ }^{[8,9]}$.

In another study by Krielessi V, Papantoniou $\mathrm{N}$ et al. they have reported $32.72 \%$ of placental calcification in association with severe pregnancy induced hypertension ( $>160 / 110 \mathrm{~mm} \mathrm{Hg}$ ) and $25.45 \%$ of calcification in association with mild hypertension $(>140 / 90 \mathrm{~mm} \mathrm{Hg})^{[10]}$.

\section{Conclusion}

The gross features of placenta varies significantly with period of gestation. Parameters such as weight, size, number of cotyledons and thickness of placenta decreases in preterm labour. The microscopic lesions observed in decreasing order of frequency were perivillous fibrin deposition (62.50\%) followed by chorioamnionitis (26.25\%), infarct $(21.25 \%)$ and calcification (17.50\%). Other pathological lesions includes villous oedema (12.50\%) and retro placental hematoma (2.50\%). All the histomorphological changes were conspicuous in preterm pregnancies.

\section{References}

1. Benirschke K, Kaufmann P. Pathology of the human placenta.2nd ed. New York: Springer Verlag; 1990.

2. Udainia A, Jain ML. Morphological study of placenta in pregnancy induced hypertension with its clinical relevance. J Anat Soc India. 2001;50:24-7.

3. Benirshke K. The placenta: How to examine it and what you can learn. Contemp Obstet Gynaecol. 1981;17:117-9.

4. Fox, $\mathrm{H}$; The placenta in intra uterine growth retardation. In Ward RHT, Smith SK, Donnai $D$ (Eds). Early foetal growth and development. RCOG Press, London, 1994; Pp : 223 - 235.

5. Adil SAK, Rumana N. A study of histo pathological changes of placenta in severe anaemia. Journal of Evolution of Medical and Dental Sciences. 2012;1(4):616.

6. Chen $\mathrm{KH}$, Chen LR et al. Exploring the relationship between preterm placental 
calcification and adverse maternal and fetal outcome. Ultrasound ObstetGynecol2011; 37: $328-334$

7. Navbir P. Placental morphology and its corelation with foetal outcome in pregnancyinduced hypertension. International Journal of Basic and Applied Medical Sciences. 2012;2(3):120-125.

8. Fox H. Pathology of the placenta. Saunders Elsevier. 2007;3: 100-103.
9. Wentworth P. Placental infarction and toxaemia of pregnancy. American Journal of Obstetrics and Gynaecology. 1967;99: 318.

10. Krielessi V, Papantoniou N, Papageorgiou I, Chatzipapas I et al. Placental pathology and blood pressure levels in women with hypertensive disorders in pregnancy. Obstetrics and Gynecology International. 2012. 